\title{
Um Cenário Da Educação Estatística Em Cursos De Pedagogia
}

\author{
Perspective Of Statistics Education In Elementary Teacher Education
}

\author{
Keli Cristina Conti* \\ Universidade Federal de Minas Gerais - (UFMG) \\ Luciana Neves Nunes* ${ }^{* *}$ \\ Universidade Federal do Rio Grande do Sul - (UFGRS) \\ Everton José Goldoni Estevam ${ }^{* * *}$ \\ Universidade Estadual do Paraná - (UNESPAR) \\ Amari Goulart ${ }^{* * * *}$
}

Instituto Federal de Educação, Ciência e Tecnologia de São Paulo - (IFSP)

\begin{abstract}
Resumo
Este artigo apresenta resultados de uma pesquisa motivada por inquietações a respeito da formação do professor que ensina Matemática nos primeiros anos da Educação Básica. O estudo objetiva traçar um cenário de cursos de Pedagogia no que diz respeito à presença da Estatística em seus currículos prescritos. O corpus do estudo consiste em instituições públicas da Região Sul do Brasil. Para a pesquisa documental, do tipo exploratória, foram obtidas informações das matrizes curriculares e súmulas/ementas das disciplinas de 37 cursos (dos 40 existentes). Para se produzirem os resultados do estudo documental foi utilizada a estatística descritiva e para a análise foram construídas nuvens de palavras, as quais se associam a uma análise qualitativa e exploratória. Os achados sugerem um desalinhamento entre as demandas apontadas pelos currículos prescritos para os Anos Inicias do Ensino Fundamental e as ementas dos cursos de Pedagogia analisados. Enquanto os currículos impõem demandas complexas para o ensino de Estatística na Educação Básica, as disciplinas do curso de formação apresentam tímida presença de saberes estatísticos, tanto aqueles específicos a se ensinar quanto os pedagógicos, demandados para ensinar Estatística. Isso evidencia, portanto, a necessidade de se reverem os componentes curriculares na formação inicial de modo a explicitar nos currículos prescritos a necessidade e intenção de desenvolver tanto conhecimentos estatísticos quanto pedagógicos relacionados à Estatística.
\end{abstract}

Palavras-chave: Formação de professores, Anos Iniciais do Ensino Fundamental, Currículo.

\footnotetext{
*Doutora em Educação (Unicamp). Professora Adjunta (UFMG), Belo Horizonte, MG, Brasil. E-mail: keli.conti@gmail.com.

${ }^{* *}$ Doutora em Epidemiologia (UFRGS). Professora Associada (UFRGS), Porto Alegre-RS, Brasil. E-mail: lununes@mat.ufrgs.br.

${ }_{* * *}$ Doutor em Ensino de Ciências e Educação Matemática (UEL). Professor Adjunto (UNESPAR), União da Vitória, PR, Brasil. E-mail: evertonjgestevam@gmail.com.

${ }^{* * * *}$ Doutor em Educação Matemática (PUC-SP). Professor da Educação Básica, Técnica e Tecnológica (IFSP), São Paulo, SP, Brasil. E-mail: amari.go@ifsp.edu.br.
} 


\begin{abstract}
This article presents results of a research motivated by concerns about the teacher education that teaches Mathematics in the first years of Basic Education. The study aims to draw a scenario of Pedagogy courses regarding the presence of Statistics in their prescribed curricula. The corpus of the study consists of public institutions of the Southern Region of Brazil. For documentary research, of the exploratory type, the information of the curricular matrices and discipline syllabus of 37 courses (of the 40 existing ones) were obtained. In order to produce the results of the document study, descriptive statistics were used and for the analysis, word clouds were constructed, which are associated to a qualitative and exploratory analysis. The findings suggest a misalignment between the demands pointed out by the curricula prescribed for the First Years of Elementary School and the discipline syllabus of the Elementary Teacher Education courses analyzed. While the curricula impose complex demands for Statistics teaching in Basic Education, the disciplines of teacher education course show a timid presence of statistical knowledge, both the specific ones to be taught and the pedagogical ones, demanded to teach Statistics. This evident, therefore, the need to review the curricular components in the initial formation in order to make explicit in the prescribed curricula the need and intention to develop both statistical and pedagogical knowledge related to Statistics.
\end{abstract}

Keywords: Teacher Education, Initial Years of Elementary Education, Curriculum.

\title{
1 Introdução
}

Este artigo, cuja versão preliminar foi apresentada no VII Seminário Internacional de Pesquisa em Educação Matemática - SIPEM ${ }^{1}$, tem como objetivo apresentar resultados de um estudo em desenvolvimento que busca traçar um panorama dos cursos de Pedagogia de instituições públicas brasileiras no que diz respeito à presença da Estatística em seus currículos prescritos. O interesse pela pesquisa surgiu a partir das discussões e atuais pesquisas do GT12 (Grupo de Trabalho sobre Educação Estatística) ${ }^{2}$ da SBEM, bem como de inquietações acerca da formação do professor que ensina Matemática nos Anos Iniciais do Ensino Fundamental, cujos apontamentos das pesquisas nacionais e internacionais indicam fragilidades e preocupações (Costa, Pinheiro \& Costa, 2016; Batanero, Burril \& Reading, 2011). Cabe ressaltar que este é um estudo em andamento e, deste modo, o artigo consiste em um recorte de uma pesquisa mais ampla. Neste trabalho são apresentados, portanto, os resultados para as instituições públicas da Região Sul do Brasil (estados do Paraná, Santa Catarina e Rio Grande do Sul), os quais apontam um cenário da Educação Estatística em cursos de Pedagogia.

\footnotetext{
${ }^{1}$ Evento promovido pela Sociedade Brasileira de Educação Matemática - SBEM. Foz do Iguaçú, Paraná, de 04 a 08 de Novembro de 2018.

${ }^{2}$ A Sociedade Brasileira de Educação Matemática - SBEM reúne 15 grupos de trabalho. Particularmente o GT12 tem como objetivo estudar e compreender como as pessoas ensinam e aprendem Estatística, o que envolve os aspectos cognitivos e afetivos do ensino-aprendizagem, além da epistemologia dos conceitos estatísticos e o desenvolvimento de métodos e materiais de ensino etc., visando ao desenvolvimento do letramento estatístico.
} 
Considerando a desejada articulação entre a formação docente e as demandas decorrentes de sua futura prática pedagógica (Batanero, 2002), o estudo é orientado pela identificação do lugar e dos modos como a formação estatística se apresenta nos currículos de Matemática da Educação Básica, com o olhar voltado, particularmente, aos Anos Iniciais do Ensino Fundamental, desde a publicação dos Parâmetros Curriculares Nacionais - PCN (Brasil, 1997) até a Base Nacional Comum Curricular - BNCC (Brasil, 2017). Estes aspectos curriculares se associam aos saberes estatísticos e pedagógicos demandados para ensinar Estatística (Burgess, 2009). Deste modo, a seção seguinte apresenta um quadro que sintetiza e articula estes aspectos, seguida dos pressupostos metodológicos que orientaram a pesquisa, tanto para a coleta de dados quanto para as análises dos resultados alcançados.

\section{A Questão Curricular Da Estatística Nos Anos Inicias Do Escola Básica E Os Saberes}

\section{Docentes}

Segundo Lopes (2010, p. 47), "a presença constante da Estatística no mundo atual tornou-se uma realidade na vida dos cidadãos, levando à necessidade de ensinar Estatística a um número de pessoas cada vez maior" e, devido a isso, muitos países passaram a inserir a Estatística nos currículos de Matemática na Educação Básica.

No Brasil, devido aos reflexos do movimento de inclusão da Estatística no currículo de Matemática, no final da década de 1990, com a publicação dos PCN (Brasil, 1997), foi incorporado oficialmente o Tratamento da Informação como um dos blocos de conteúdos da estrutura curricular de Matemática. Ele orienta o currículo mínimo dessa disciplina relacionado à Probabilidade, Estatística e Combinatória para as diversas faixas etárias dos estudantes, dos Anos Iniciais do Ensino Fundamental ao Ensino Médio.

Neste contexto, o currículo de Matemática para a Educação Infantil, destinada a crianças de até 5 anos e 11 meses de idade, foi estabelecido pelo Referencial Curricular Nacional para a Educação Infantil - RCNEI (Brasil, 1998). Esse documento organiza os conteúdos matemáticos em três blocos: Números e Sistema de Numeração, Grandezas e Medidas e Espaço e Forma. Infelizmente, o RCNEI não traz um bloco de conteúdos explícito sobre essa área, a do Tratamento da Informação, pois, quando de sua publicação, as pesquisas quanto à inserção da Educação Estatística na Educação Infantil ainda estavam se iniciando. Mesmo no documento de Revisão das Diretrizes Curriculares Nacionais para a Educação Infantil (Brasil, 2010), aprovado em 11/11/2009, não há menção ao trabalho com a Estatística. Diferentemente dos 
documentos oficiais voltados para a Educação Infantil, defendemos o ensino de Estatística nesta faixa etária porque segundo Fischbein (1975), citado por Lopes (2012, p. 165-166),“[...] o ensino de estatística deveria ocorrer desde a infância, pois o trabalho com essa temática, além de ser viável no início da escolaridade, também pode evitar que as pessoas enraízem intuições errôneas sobre o movimento aleatório".

Os PCN (Brasil, 1997) para o Ensino Fundamental, destinado a estudantes de 6 a 14 anos, orientam o que deve ser trabalhado referente aos quatro grandes blocos de conteúdos: Números e Operações; Espaço e Forma; Grandezas e Medidas; e Tratamento da Informação. Ainda nos PCN (Brasil, 1997), encontramos, nos objetivos gerais do Ensino Fundamental, explicitamente, inúmeros aspectos relacionados ao desenvolvimento da competência estatística, como "cidadania", "exercício de direitos e deveres", "posicionar-se de maneira crítica”, "tomar decisões", "utilizar as diferentes linguagens", "saber utilizar as diferentes fontes de informação", entre outros.

Com relação ao bloco Tratamento da Informação, os PCN propõem os seguintes conteúdos para o primeiro ciclo do Ensino Fundamental (1. ${ }^{\circ}$ ao $5 .^{\circ}$ ano):

- Leitura e interpretação de informações contidas em imagens.

- Coleta e organização de informações.

- Criação de registros pessoais para comunicação das informações coletadas.

- Exploração da função do número como código na organização de informações (linhas de ônibus, telefones, placas de carros, registros de identidade, bibliotecas, roupas, calçados).

- Interpretação e elaboração de listas, tabelas simples, de dupla entrada, gráficos de barra para comunicar a informação obtida.

- Produção de textos escritos a partir da interpretação de gráficos e tabelas. (Brasil, 1997, p. 52)

Mais recentemente, o Pacto Nacional pela Alfabetização na Idade Certa - PNAIC (Brasil, 2014, p. 30) ${ }^{3}$ expressa que a alfabetização matemática, na perspectiva do letramento, deve promover a "apropriação pelos aprendizes de práticas sociais de leitura e escrita de diversos tipos de texto, práticas de leitura e escrita do mundo - não se restringe ao ensino do sistema de numeração e das quatro operações aritméticas fundamentais". No material de formação do PNAIC, adotou-se a expressão "direitos da aprendizagem" para indicar a compreensão de educação escolar como direito social (Brasil, 2014). Esse material apresenta, a partir dos direitos básicos de aprendizagem em Matemática, cinco eixos estruturantes: Números e Operações; Pensamento Algébrico; Espaço e Forma/Geometria; Grandezas e

\footnotetext{
${ }^{3}$ Programa Oficial de Formação e acordo formal assumido pelo governo federal, pelo Distrito Federal, por estados, municípios e entidades para firmar o compromisso de alfabetizar crianças até, no máximo, 8 anos de idade, ao final do ciclo de alfabetização.
} 


\section{Medidas; e Tratamento da Informação/Estatística e Probabilidade.}

O Tratamento da Informação, que neste material é denominado Educação Estatística, apresenta os seguintes objetivos:

- Ler, interpretar e fazer uso das informações expressas na forma de ícones, símbolos, signos, códigos; em diversas situações e em diferentes configurações (anúncios, gráficos, tabelas, rótulos, propagandas), para compreensão de fenômenos e práticas sociais;

- Formular questões sobre fenômenos sociais que gerem pesquisas e observações para coletar dados quantitativos e qualitativos;

- Coletar, organizar e construir representações próprias para a comunicação de dados coletados (com ou sem uso de materiais manipuláveis ou de desenhos);

- Ler e interpretar listas, tabelas simples, tabelas de dupla entrada, gráficos;

- Elaborar listas, tabelas simples, tabelas de dupla entrada, gráficos de barras e pictóricos para comunicar a informação obtida, identificando diferentes categorias;

- Produzir textos escritos a partir da interpretação de gráficos e tabelas;

- Problematizar e resolver situações a partir das informações contidas em tabelas e gráficos. (Brasil, 2014, p. 55)

Finalmente, nos últimos anos, tivemos a promulgação da BNCC (Brasil, 2017), na qual “a incerteza e o tratamento de dados são estudados na unidade temática Probabilidade e Estatística" (p. 230). O documento é estruturado em objetos do conhecimento associados a habilidades específicas, situados em cada ano/série do Ensino Fundamental e em cada uma das cinco unidades temáticas que orientam a organização do documento - além da Probabilidade e Estatística, Números, Álgebra, Geometria, e Grandezas e Medidas. O Quadro 1 sintetiza esses objetos relacionados à unidade temática Probabilidade e Estatística nos cinco anos iniciais do Ensino Fundamental.

Quadro 1: Objetos matemáticos previstos na BNCC relacionados à unidade temática Probabilidade e Estatística para os anos iniciais

\begin{tabular}{|c|c|}
\hline Ano & Objeto(s) \\
\hline $1^{\mathrm{o}}$ & $\begin{array}{ll}\square & \text { Noção de acaso. } \\
\square & \text { Leitura de tabelas e de gráficos de colunas simples. } \\
\square & \text { Coleta e organização de informações. } \\
\square & \text { Registros pessoais para comunicação de informações coletadas. }\end{array}$ \\
\hline $2^{o}$ & $\begin{array}{l}\square \text { Análise da ideia de aleatório em situações do cotidiano. } \\
\square \text { Coleta, classificação e representação de dados em tabelas simples e de dupla entrada e em } \\
\text { gráficos de colunas. }\end{array}$ \\
\hline $3^{\circ}$ & $\begin{array}{l}\square \text { Análise da ideia de acaso em situações do cotidiano: espaço amostral. } \\
\square \text { Leitura, interpretação e representação de dados em tabelas de dupla entrada e gráficos de barras. } \\
\square \text { Coleta, classificação e representação de dados referentes a variáveis categóricas, por meio de } \\
\text { tabelas e gráficos. }\end{array}$ \\
\hline $4^{\circ}$ & $\begin{array}{l}\square \quad \text { Análise de chances de eventos aleatórios. } \\
\square \quad \text { Leitura, interpretação e representação de dados em tabelas de dupla entrada, gráficos de colunas }\end{array}$ \\
\hline
\end{tabular}




\begin{tabular}{|c|c|}
\hline Ano & Objeto(s) \\
\hline & $\begin{array}{l}\text { simples e agrupadas, gráficos de barras e colunas e gráficos pictóricos. } \\
\square \text { Diferenciação entre variáveis categóricas e variáveis numéricas. } \\
\square \text { Coleta, classificação e representação de dados de pesquisa realizada. }\end{array}$ \\
\hline $5^{\circ}$ & $\begin{array}{l}\square \text { Espaço amostral: análise de chances de eventos aleatórios. } \\
\text { Cálculo de probabilidade de eventos equiprováveis. } \\
\square \text { Leitura, coleta, classificação interpretação e representação de dados em tabelas de dupla } \\
\text { entrada, gráfico de colunas agrupadas, gráficos pictóricos e gráfico de linhas. }\end{array}$ \\
\hline
\end{tabular}

Fonte: Brasil (2017)

Segundo Batanero (2002), o fato de conteúdos estatísticos fazerem parte dos currículos oficiais não significa que sejam ensinados nos diversos níveis escolares, pois, paralelamente às questões curriculares, surgem as questões de formação dos professores. Não obstante, Batanero et al. (2011) salientam que, em âmbito mundial, poucos professores da escola primária ${ }^{4}$ têm recebido formação estatística de modo a lhes proporcionar o conhecimento didático de que precisam, o que compromete a efetivação de propostas em sala de aula.

Neste contexto, admitimos os conteúdos da Educação Básica, particularmente dos anos iniciais do Ensino Fundamental, reconhecidos como direitos de aprendizagem ou unidades temáticas nos documentos oficiais, para perquirir a formação do professor que ensina Matemática neste nível de ensino, sua formação para o trabalho com a Estatística e os saberes demandados ao seu exercício profissional. Sobre estes últimos, Valente, Bertini e Morais (2017) apontam dois saberes profissionais articulados dos professores que ensinam Matemática: os saberes a ensinar e os saberes para ensinar. De acordo com os autores,

O primeiro deles - os saberes a ensinar - referem-se aos saberes produzidos pelas disciplinas universitárias, pelos diferentes campos científicos considerados importantes para a formação dos professores; o segundo, os saberes para ensinar, têm por especificidade a docência, ligam-se àqueles saberes próprios para o exercício da profissão docente. Assim, ambos os saberes constituem-se como saberes da formação de professores, mas a expertise profissional, o que caracteriza a profissão de professor, é a posse dos saberes para ensinar. (Valente, Bertini \& Morais, 2017, p. 228)

Dessa forma, os conteúdos estatísticos presentes no currículo de Matemática dos Anos Iniciais sugerem tanto saberes a ensinar quanto saberes para ensinar Estatística esperados do professor atuante nesse nível de ensino, os quais devem, portanto, estar presentes nos componentes curriculares dos cursos de Pedagogia. Apoiando-nos em Burgess (2009),

\footnotetext{
${ }^{4}$ De acordo com a estrutura do sistema de ensino brasileiro, a Educação Primária corresponde aos anos iniciais do Ensino Fundamental.
} 
admitimos que os saberes estatísticos a ensinar significam os conceitos, procedimentos e ideias estatísticas comum a outras profissões, no sentido operacional da Estatística, o que abarca particularmente aqueles referidos nos currículos dos Anos Iniciais do Ensino Fundamental acaso, aleatório, variáveis, construção e interpretação de tabelas e gráficos e as etapas de um processo investigativo. Já os saberes para ensinar Estatística envolvem a capacidade de: analisar a adequabilidade das produções dos alunos, as representações e os registros utilizados, incluindo os erros cometidos; antecipar pensamentos em relação a determinadas ideias, conceitos e procedimentos estatísticos; identificar o que os alunos poderão julgar fácil ou difícil, bem como, reconhecer estratégias pedagógicas mais adequadas para abordagem de determinado conteúdo estatístico.

Considerando este cenário, a seção seguinte esclarece os aspectos metodológicos que orientaram a pesquisa.

\section{Aspectos Metodológicos Da Pesquisa}

Devido às inquietações a respeito da formação do professor que ensina Matemática nos primeiros anos da Educação Básica, licenciado em Pedagogia, e à questão dos saberes profissionais relativos a um conteúdo específico, propusemos este estudo, que se caracterizou como uma pesquisa documental do tipo exploratória.

Com o objetivo de traçar um cenário da presença da Estatística nos currículos prescritos em cursos de Pedagogia, fizemos um levantamento dos projetos pedagógicos, matrizes curriculares e ementas/súmulas de Instituições Estaduais, Federais e Municipais (públicas) de Ensino Superior da Região Sul do Brasil que ofertam esse curso. Estamos considerando como currículo prescrito o currículo formal que, de certa forma, regula o processo educativo em determinado contexto em que é utilizado, como balizador das práticas pedagógicas e da avaliação.

Os dados iniciais para análise foram obtidos a partir do site do Ministério da Educação - $\mathrm{MEC}^{5}$, considerando as instituições públicas que ofertam o curso de Pedagogia na modalidade presencial. Eles consistiram em nome da instituição, unidade de federação (UF), cidade sede e notas da última avaliação de cursos realizada pelo MEC. Para a pesquisa documental foram consideradas como fontes de informação os documentos disponibilizados pelos cursos de Pedagogia em seus projetos pedagógicos ou matrizes curriculares, em geral apresentados nos

\footnotetext{
${ }^{5}$ http://emec.mec.gov.br/
} 
sites das instituições ou disponibilizados pelos coordenadores de curso, via solicitação por correio eletrônico. A coleta dos dados foi realizada por diferentes pesquisadores, autores deste trabalho, que seguiram um roteiro para identificar, em cada currículo, as disciplinas que poderiam envolver conteúdos de Estatística e Educação Estatística, geralmente associadas à Matemática. A partir do nome de cada disciplina, o pesquisador incluiu-a ou não no corpus analítico da pesquisa. Nas denominações das disciplinas incluídas na lista deveriam constar algum(ns) do(s) seguinte(s) termo(s): Matemática, Educação Matemática, Estatística ou Educação Estatística. Em uma segunda etapa, analisou-se a ementa/súmula das disciplinas desta lista com vistas a identificar a natureza dos saberes envolvidos e se ela incluía efetivamente os conteúdos de Estatística ou Educação Estatística. Em decorrência desta análise as disciplinas foram classificadas em três grupos: (i) saberes matemáticos a ensinar (SME), que incluem disciplinas cujas ementas referem essencialmente conteúdos de Matemática (e Estatística) com foco na instrumentalização do (futuro) pedagogo para operacionalizá-los, não necessariamente em sala de aula; (ii) saberes para ensinar Matemática (SPM), referindo as disciplinas que explicitavam em suas ementas o foco pedagógico condizente ao ensino de Matemática (e Estatística) na Educação Infantil e nos Anos Iniciais do Ensino Fundamental; (iii) saberes pedagógicos gerais (SPG), cujas ementas evidenciam o foco pedagógico da disciplina sem referir explicitamente a Matemática ou a Estatística. A partir desta classificação inicial, nas ementas daquelas disciplinas classificadas em (i) e (ii), foram perquiridos indícios que permitissem referir sua incidência, respectivamente, em saberes estatísticos a ensinar (SEE) e saberes para ensinar Estatística (SPE), gerando outras duas subcategorias de classificação, cujas disciplinas referem, portanto, explicitamente sua incidência em campos da Estatística ou da Educação Estatística. Todas as ementas foram classificadas pelos quatro pesquisadores, de forma independente, nas categorias SME, SPM e SPG e, em seguida, em SEE e SPE, sendo sua classificação final definida quando da concordância de pelo menos três dos pesquisadores envolvidos no trabalho.

Para se produzir os resultados dessa análise de documentos foi utilizada a estatística descritiva, através do software SPSS versão 18.0. Como ferramenta de apoio para a análise qualitativa dos dados, de cunho exploratório, foram geradas nuvens de palavras com o aplicativo online WordArt. 


\section{A Estatística Nos Cursos De Pedagogia No Brasil - Região Sul}

No Brasil, são 158 instituições públicas que oferecem o curso de Pedagogia, na modalidade presencial, totalizando 664 cursos. Em relação às regiões brasileiras, 14 instituições (8,9\%) ficam no Centro-Oeste, 34 (21,5\%) no Nordeste, 21 (13,3\%) no Norte, 49 (31,0\%) no Sudeste e 40 (25,3\%) no Sul. Das instituições da Região Sul, 17 (42,5\%) estão localizadas em Santa Catarina, 16 (40,0\%) no Paraná e 7 (17,5\%) no Rio Grande do Sul.

A partir da identificação de todas as instituições da região Sul, foco deste artigo, foi possível obter informações sobre as matrizes curriculares e ementas/súmulas das disciplinas de 31 instituições (das 40 existentes) por meio das páginas da WEB das instituições ou contato via correio eletrônico, totalizando 37 cursos $^{6}$. Ao se identificar quantas e quais disciplinas poderiam abordar o conteúdo de Estatística ou Educação Estatística, verificou-se que os cursos se distribuem da seguinte forma: $16(43,2 \%)$ têm uma disciplina, 19 (51,4\%) têm duas e $2(5,4 \%)$ têm três, totalizando 60 disciplinas distribuídas nos 37 cursos analisados. O conjunto das disciplinas em cada curso, em média, tem carga horária de 111 horas ( $\mathrm{DP}=44,4$ horas). Quanto ao período, 66,7\% dos cursos ofertam todas as disciplinas na segunda metade do curso, enquanto os demais se distribuem ao longo das 3200 horas mínimas previstas para o curso.

Os nomes das disciplinas incluídas neste estudo remetem à formação matemática dos futuros pedagogos e, a partir desses nomes, chegou-se à nuvem de palavras apresentada na Figura 1. Essa representação indica que as maiores frequências consistem nas palavras matemática (52 ocorrências), ensino (27 ocorrências), metodologia (20 ocorrências) e educação (15 ocorrências). A palavra estatística apareceu somente seis vezes entre todos os nomes das disciplinas analisadas.

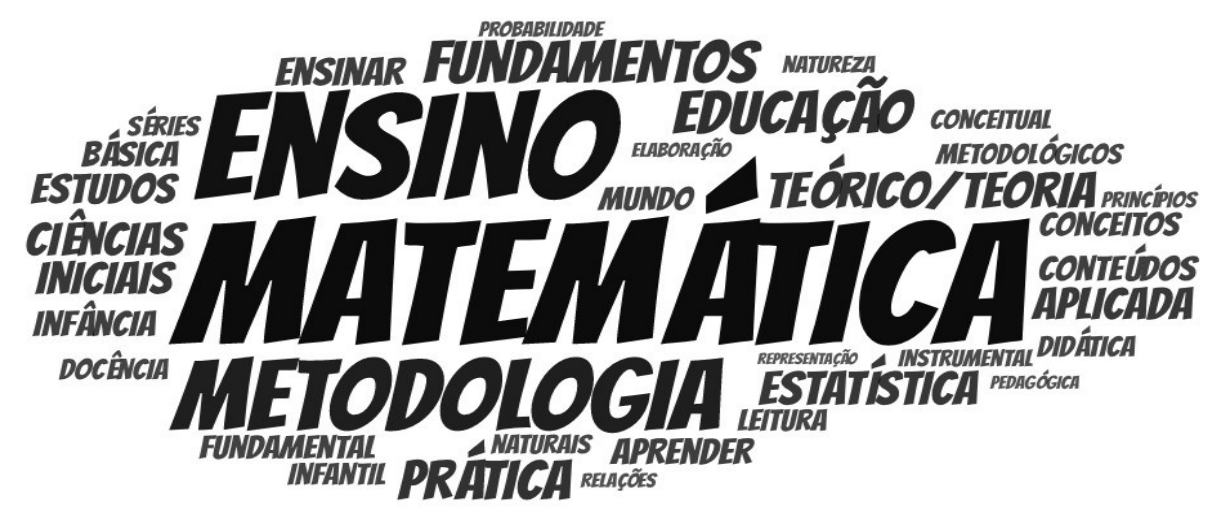

${ }^{6}$ Há instituições que oferecem o curso de Pedagogia em várias unidades/campi. 
Figura 1: Nuvem de palavras a partir do nome das disciplinas presentes nos 37 cursos de Pedagogia analisados Fonte: Elaborado pelos autores

Foram obtidas as informações das ementas/súmulas de 49 disciplinas através das páginas da WEB ou de contatos com as coordenações dos cursos, o que representa 81,7\% das disciplinas identificadas na primeira etapa do estudo $(n=60)$. Para 11 disciplinas identificadas na primeira etapa da coleta de dados, não se obteve quaisquer informações sobre as súmulas/ementas, pois não estavam disponíveis na WEB e os contatos realizados não foram retornados até a data de finalização deste artigo. Da classificação inicial das ementas/súmulas das disciplinas identificou-se que a maior parte delas, $40(81,6 \%)$, refere-se a saberes para ensinar Matemática (SPM), sendo que $6(12,3 \%)$ referem-se a saberes matemáticos a ensinar (SME) e outras $3(6,1 \%)$ a saberes pedagógicos gerais (SPG) (ainda que os critérios de seleção das disciplinas tenham levado em consideração, que tivessem como foco a Matemática). Estes índices, por sua vez, são resultado da classificação das disciplinas de SPM e SME em respectivas subcategorias que referem explicitamente saberes estatísticos explicitados nas ementas das disciplinas analisadas. Entre as 49 disciplinas, 17 (34,7\%) foram classificadas nessas duas subcategorias, das quais $5(10,2 \%)$ referem saberes estatísticos a ensinar (SEE) e $12(24,5 \%)$ saberes para ensinar Estatística.

A partir das ementas/súmulas das disciplinas foi gerada uma nuvem de palavras para se analisar com que frequência aparecem referências a termos que podem estar associados a conteúdos estatísticos. A Figura 2 mostra essa representação, a qual considerou as palavras que se repetiram no mínimo três vezes. A fim de se construir a nuvem, algumas palavras e suas variações foram consideradas conjuntamente em sua frequência, como por exemplo, a palavra fundamento, que está junto com fundamentos e fundamental.

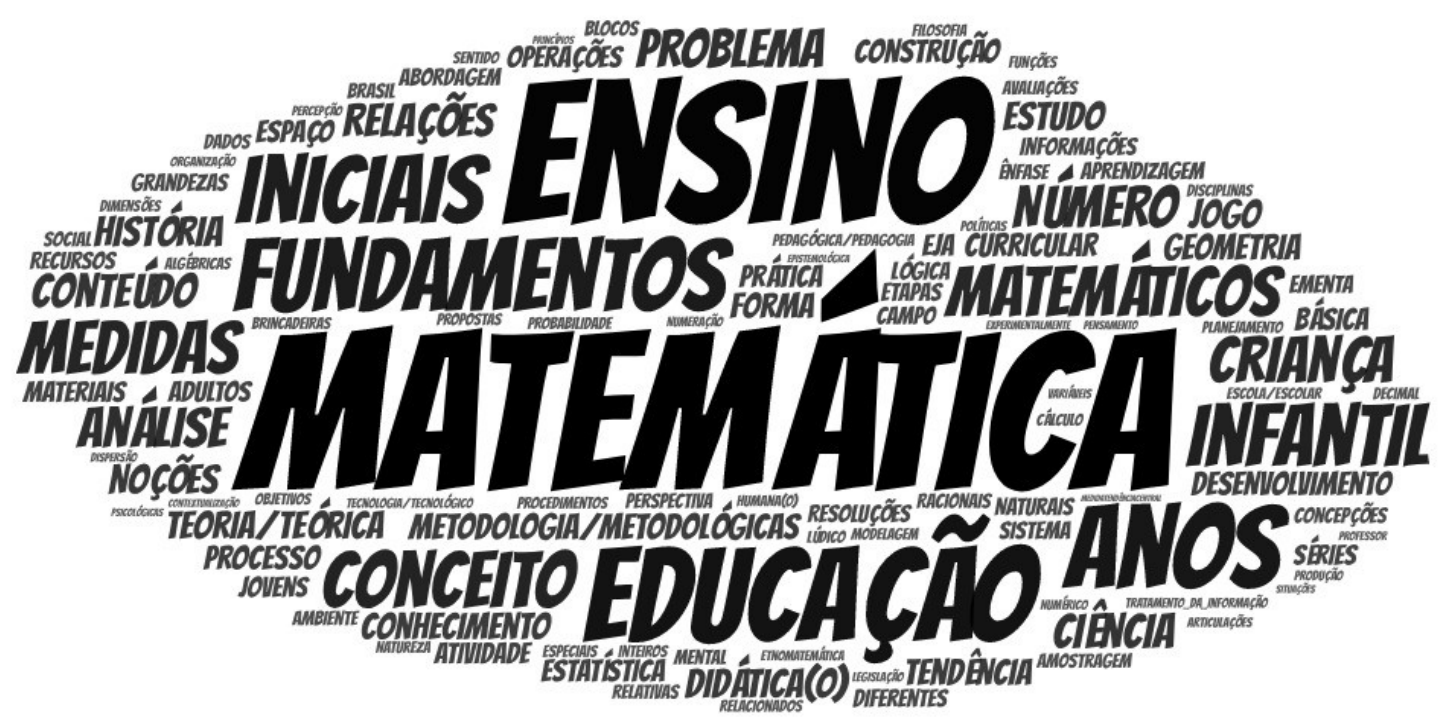

Figura 2: Nuvem de palavras a partir da ementa/súmula das disciplinas dos 37 cursos de Pedagogia analisados 
Fonte: Elaborado pelos autores

Nas ementas/súmulas avaliadas, destacam-se a palavra Matemática, que aparece 101 vezes, e ainda a palavra matemáticos, que aparece 22 vezes. As demais palavras com maior ocorrência foram: ensino (83 ocorrências) e educação (44 ocorrências). Estas ocorrências demonstram que as ementas dos cursos não tendem a explicitar os blocos ou unidades temáticas envolvidos no currículo de Matemática da Educação Básica, mas aspectos gerais relacionados a seu ensino e aprendizagem. Por exemplo, a palavra estatística apareceu 12 vezes, sendo que em 10 casos referem disciplinas de SEE, que não focalizam aspectos do/para o ensino de estatística. Já a expressão tratamento da informação, bloco referido nos PCN, apresentou 10 ocorrências, todas elas em disciplinas de SPE, como seria esperado. Outras palavras e expressões como geometria (9 ocorrências) e grandezas e medidas (8 ocorrências) corroboram a tímida explicitação dos blocos específicos relacionados aos saberes matemáticos, objeto da atuação do professor dos Anos Inicias do Ensino Fundamental nas ementas/súmulas analisadas. A exceção consiste nas palavras números, com 18 ocorrências, e operações com outras 12, sugerindo que os saberes matemáticos priorizados/explícitos na formação do pedagogo referem o bloco de conteúdos ou unidade temática Números e Operações. Dessa forma, se a abordagem de Matemática nas matrizes curriculares para a formação do pedagogo tem mostrado uma presença tímida (Costa et al., 2016), quando se observa os saberes particulares relacionados à atuação do pedagogo, este cenário se agrava.

Considerando o foco deste trabalho, salienta-se ainda que outras palavras que referem aspectos particulares da estatística como amostragem (5 ocorrências), probabilidade (5 ocorrências), aleatório (2 ocorrências), inferência (2 ocorrências), e gráfico (1 ocorrência) referem exclusivamente SEE, com vistas a instrumentalizar o professor naquelas disciplinas de Estatística Aplicada.

Considerando que as propostas curriculares do nosso país devem embasar o que ocorre nas salas de aula da Educação Básica, particularmente quanto aos conteúdos, é preciso considerar que já se passaram 22 anos (1997-2019) desde a inclusão desse bloco de conteúdos relativos à Probabilidade e Estatística (Brasil, 1997). Fato reafirmado pela presença da unidade temática "Probabilidade e Estatística", seus objetos de conhecimento e habilidades na BNCC (Brasil, 2017), com a inclusão ainda mais cedo daqueles relativos à Probabilidade (a partir do 1. ${ }^{\circ}$ ano do Ensino Fundamental). Contudo, infelizmente, a formação do profissional que necessita trabalhar com esses conteúdos nos Anos Iniciais do Ensino Fundamental ainda parece não ser a ideal, no que tange à Matemática e, em especial, à Estatística, já que elementos que evidenciem sua presença nos currículos prescritos dos cursos de Pedagogia são tímidos nas 
ementas dos cursos analisados.

Para além da exígua presença da Estatística, as nuvens de palavras evidenciam um aspecto complementar e essencial para nossas análises. A escassez de termos associados à Estatística e, por outro lado, a presença significativa de termos relacionados à educação e ao ensino denotam a dissociação da estatística das dimensões pedagógicas associadas ao seu ensino. Isso porque os termos identificados relacionados à Estatística estão presentes em denominações e súmulas/ementas de disciplinas relacionadas à aplicação dos recursos estatísticos nas atividades de gestão do pedagogo, em detrimento de abordagens pedagógicas. Estas últimas parecem referir à Matemática em dimensão ampla, desconsiderando, por exemplo, as particularidades e demandas inerentes ao pensamento e raciocínio estatísticos, evidenciados pelas pesquisas de Lopes (2010; 2012), Batanero et al. (2011), entre outros.

Há que se considerar que, provavelmente, o professor, ao concluir o curso de Pedagogia, pode não se sentir preparado para trabalhar com ideias de aleatoriedade, noções de acaso, planejamento de pesquisas e coleta de dados, bem como o trabalho de organização desses dados e apresentação/discussão de resultados aos estudantes, envolvendo gráficos e tabelas, por exemplo. Por conseguinte, podemos apontar que nem sempre o professor irá empreender em seu currículo praticado ou em sua ação na escola, em termos teóricos ou metodológicos, o que está prescrito pelos documentos curriculares brasileiros, conforme salienta Batanero (2002). Em diversos aspectos, todos saem perdendo, em especial os estudantes.

Cabe salientar ainda que os títulos e as ementas/súmulas das disciplinas podem não ser suficientes para evidenciar, de fato, a formação relacionada à Estatística nos cursos de Pedagogia analisados. Contudo, tais documentos constituem as orientações fundantes dos conteúdos programáticos e das ações constituintes dessas disciplinas e, portanto, a tímida presença identificada sobre a Estatística (e igualmente a outros blocos de conteúdos ou unidades temáticas) sugere, no mínimo, uma fragilidade nos currículos prescritos que, provavelmente, se reflete naquele efetivado em sala de aula e, por conseguinte, na formação oferecida aos pedagogos. Isso porque, aparentemente, ficam comprometidos tanto seu conhecimento relacionados aos saberes estatísticos a ensinar, bem como, e especialmente, os saberes para ensinar Estatística, o que, de acordo com Valente et al. (2017), é substancialmente prejudicial para a formação deste futuro profissional da educação, responsável pela iniciação matemática e estatística das crianças no processo formal de educação. 


\section{Considerações Finais}

Com objetivo de traçar um cenário dos cursos de Pedagogia, das instituições públicas brasileiras, no que se refere ao trabalho com os conteúdos relativos à Estatística na formação de professores, realizamos esta pesquisa, cujo recorte abarcou o cursos presenciais de instituições públicas da Região Sul do Brasil, as quais representam 25,3\% das instituições brasileiras em condições semelhantes. Infelizmente, nossas inquietações permanecem ao constatar que a Estatística, ou a Educação Estatística, ainda não é valorizada nos currículos das 37 instituições pesquisadas, seja no que se refere aos saberes estatísticos a ensinar, inerentes às diversas áreas do conhecimento e a outros profissionais, ou particularmente àqueles saberes para ensinar Estatística, os quais incidem e afetam diretamente as práticas pedagógicas realizadas em sala de aula.

Nosso estudo expressa um desalinhamento entre as demandas apontadas pelos currículos prescritos para os Anos Inicias do Ensino Fundamental e as ementas dos cursos de Pedagogia analisados. Enquanto os primeiros sugerem a abordagem de noções de acaso e de aleatório, cálculo de probabilidades, classificação de variáveis, tabelas e gráficos de colunas, bem como a elaboração e condução de um processo investigativo, saberes estes extremamente complexos tanto do ponto de vista da Estatística quando do ensino de Estatística, as ementas analisadas pouco ou nada trazem relacionado à Estatística (em ambas naturezas de saberes) e, portanto, às ideias presentes nas orientações curriculares para os Anos Iniciais da Educação Básica. Neste sentido, parece que o professor necessita trabalhar em sua prática profissional conteúdos e ideias estatísticas que sequer são abordados em sua formação. Isso evidencia, portanto, a necessidade de rever os componentes curriculares dos cursos de Pedagogia, de modo a desenvolver tanto conhecimentos estatísticos quanto pedagógicos relacionados à Estatística saberes a ensinar e para ensinar Estatística.

Este indicativo pode também ser ampliado para referir outros blocos ou unidades temáticas presente no currículo dos Anos Iniciais do Ensino Fundamental, para além de Números e Operações que, embora signifiquem saberes fundamentais, não são suficientes à alfabetização matemática das crianças. Ademais, os resultados sugerem igualmente a pertinência de estudos voltados à investigação da presença da Matemática no cursos de Pedagogia (e outros semelhantes) aprofundarem seu foco analítico em saberes específicos à profissão docente, em detrimento de observações macros assentes na consideração ampla da Matemática. Isso porque enquanto estes últimos tendem a evidenciar a presença ou ausência da 
Matemática nestes espaços formativos, a especialização do foco permite explicitar formas e a natureza dos saberes relevados nestes espaços.

Por fim, considerando a delimitação metodológica do corpus da pesquisa aqui apresentada, há que se ponderar suas limitações. Deste modo, traçamos como metas de continuidade e de outros estudos a investigação dos cursos de Pedagogia das instituições públicas de outras regiões brasileiras, de instituições privadas e na modalidade à distância, a fim de elaborar um panorama ampliado que pode ou não corroborar os achados ora apresentados. Outro aspecto consiste no aprofundamentos dos resultados alcançados com a análise das matrizes e ementas/súmulas das disciplinas do curso a partir da observação de Planos de Ensino das disciplinas e de entrevistas ou questionários direcionados aos docentes que atuam com estas disciplinas nos cursos de Pedagogia.

De qualquer modo, esperamos que estes trabalhos encontrem cenários mais promissores em relação à formação do futuro professor que trabalhará com o conteúdo da Estatística no componente curricular da Matemática nos Anos Inicias do Ensino Fundamental e, igualmente, que os apontamentos salientados possam orientar a (re)estruturação de cursos de Pedagogia do país, bem como as políticas e ações de formação inicial e continuada direcionadas a estes (futuros) profissionais.

\section{Referências}

Batanero, C. (2002). Los retos de la cultura estadística. In Anais das Jornadas Interamericanas de Enseñanza de la estadística, Buenos Aires, Argentina. Recuperado de http://www.ugr.es/ batanero/ARTICULOS/CULTURA.pdf.

Batanero, C., Burril, G. \& Reading, C. (2011). Overview: challenges for teaching statistics in school mathematics an preparing mathematics teachers. In C. Batanero, G. Burril, \& C. Reading. (Ed.). Teaching statistics in school mathematics - challenges for teaching and teacher education: a JointICMI/IASI study. London: Springer.

Brasil. Ministério da Educação e do Desporto. (1997). Parâmetros Curriculares Nacionais: matemática. Brasília: SEF.

Brasil. Ministério da Educação e do Desporto. (1998). Referencial Curricular Nacional para a Educação Infantil. Brasília: SEI.

Brasil. Ministério da Educação. (2014). Pacto nacional pela alfabetização na idade certa: Educação Estatística. Brasília: SEFr.

Brasil. Ministério da Educação. (2017). Base Nacional Comum Curricular. Brasília: SEF.

Burgess, T. A. (2009). Teacher knowledge and statistics: what types of knowledge are used in 
the primary classroom? The Montana Mathematics Enthusiast, 6(1-2), 3-24.

Costa, J. M., Pinheiro, N. A. M., \& Costa, E. (2016). A formação para matemática do professor de anos iniciais. Ciênc. Educ., 22(2), 505-522.

Fishbein, E. (1975). The intuitive sources of probabilistic thinking in children. Dordrecht/Holland: D. Reidel.

Lopes, C. A. E. (2010). Os desafios para Educação Estatística no currículo de Matemática. In C. E. Lopes, C. Q. S. Coutinho, \& S. A. Almouloud (Orgs.). Estudos e reflexões em Educação Estatística. Campinas: Mercado de Letras.

Lopes, C. E. (2012). A educação estocástica na infância. Revista Eletrônica de Educação, 6(1), 160-174.

SPSS Inc. Released 2009. PASW Statistics for Windows, Version 18.0. Chicago: SPSS Inc.

Valente, V. R., Bertini, L. F., \& Morais, R. S. (2017, mar./abr.). Novos aportes teóricometodológicos sobre os saberes profissionais na formação de professores que ensinam Matemática. Acta Scientiae, 19(2), 224-235.

Submetido em: 30/03/2019

Aceito em 07/09/2019 